\title{
Fluidized bed device processing simulation of industrial Smelting waste water fluoride in experimental study
}

\author{
Qian Guan ${ }^{1, a^{*}}$,Yang Yang ${ }^{2, b}$, Luyi Yao ${ }^{3, c}$,Xingzhen Sui ${ }^{4, d}$
}

\author{
${ }^{1}$ School of International Education of Nanchang Hangkong University; Key Laboratory of Jiangxi \\ Province for Persistent Pollutants Control and Resources Recycle, Nanchang Hangkong University, \\ Nanchang of China, 330063 \\ ${ }^{2}$ School of International Education of Nanchang Hangkong University, Nanchang of China, 330063 \\ ${ }^{3}$ School of International Education of Nanchang Hangkong University, Nanchang of China, 330063 \\ ${ }^{4}$ Key Laboratory of Jiangxi Province for Persistent Pollutants Control and Resources Recycle, \\ Nanchang Hangkong University, Nanchang of China, 330063 \\ agq520421@163.com, ${ }^{\text {byylucy97@@qq.com, }{ }^{c} 994602082 @ q q . c o m,{ }^{d} 794879803 @ q q . c o m}$
}

Keywords: fluidized bed; Rare earth; Fluoride; Calcium fluoride

\begin{abstract}
Using fluidized bed under the action of high fluoride on simulation of jiangxi rare rare earth smelting waste water to remove the test. Articles by controlling the F/Ca, change CaF2 (AR) particle size and so on has carried on the related experiment, and the output of the crystal were characterized, and the experimental results show that the change of CaF2 (AR) particle size effect on fluoride in effect is not big, but when the control F/Ca is 0.6 , namely the $\mathrm{F}-300 \mathrm{mg} / \mathrm{L}, \mathrm{Ca} 2+$ is $500 \mathrm{mg} / \mathrm{L}$ when can achieve a certain amount of fluoride in effect, the $\mathrm{F}$ - concentration drops to about $10 \mathrm{mg} / \mathrm{L}$. Conclusion: effective control in the fluidized bed reaction conditions conducive to $\mathrm{Ca} 2+$, as well as the combination of $\mathrm{F}$ - and CaF2 crystal growth at the same time to achieve the ideal effect of fluoride.
\end{abstract}

\section{Introduction}

Jiangxi rare earth resource is abundant in China, and its unique resources. But the rare rare earth smelting enterprise easy to generate a large number of difficult to deal with wastewater containing fluorine, the concentration is in commonly $1.22 .8 \mathrm{~g} / \mathrm{L}, \mathrm{PH}<2$ [1]. High fluoride wastewater in view of the smelting, scholars generally accepted methods or using calcium salt treatment, the method has simple process, easy processing, etc [2] by using calcium salt treatment, however, had to be involved in the growth of calcium fluoride crystals, precipitation, etc. Series process [3]. Therefore, if the related crystallization method which can effectively, can the depth of the rare and rare earth metal smelting wastewater containing fluorine removal, reduce environmental pollution.

Fluoride wastewater treatment methods at home and abroad a lot, including adsorption method [4], electrocoagulation method [5-6], reverse osmosis membrane [7] [8], ion exchange method and other new technology. , however, these methods operation cost is high, the process is complex, especially for high fluoride wastewater treatment efficiency is obviously low, after processing the fluorine ion concentration in the waste water discharge, as a general rule, be $15 \mathrm{mg} / \mathrm{L}$, the calcium fluoride is mostly a gel, also hard to precipitation separation, cause great challenge to calcium fluoride resource utilization, serious causes the waste of resources, but also cause serious challenges 
to the ecological environment. At present a new method of fluoride in a large study by scholars at home and abroad, is fluidized crystallization, and compared with the traditional chemical precipitation process, the key characteristics of fluidized crystallization is laminar fluidized bed effect, fluidization system belongs to the mixture of particles and fluid composition. Fluidized solid particles in the working process of the physical and chemical performance have been improved and strengthened and has many advantages, has become a current research hot spot, has quite a wide application prospect. In principle, fluidized crystallization process can all can be in the form of salt crystals precipitation of material removal from the water, including water softening, heavy metal, phosphate, fluorine removal and recycling, therefore fluidized crystallization method is a feasible method of fluoride in [9, 10-15).

Using fluidized crystallization can be flocculation, sedimentation, and a series of process of mixed together, and fluidized bed has the cover an area of an area small, low cost, simple operation etc., is a kind of ideal crystallization technology. Basic principle of fluidized crystallization reaction is through appropriate seed is added in the fluidized bed reactor, using appropriate water conditions make the seed presents fluidization, under the effect of seed induced to form F - and Ca2 + CaF2 [16], under the action of precipitant acceleration generated calcium fluoride crystals precipitated. This article will further in-depth study fluidized bed fluoride in related experiment, provide theoretical basis for fluoride in aspects of scholars.

\section{Experimental}

Sodium fluoride, anhydrous calcium chloride, 100-400 mesh granular quartz (SiO2), potassium nitrate, fluoride ion concentration meter.

Will sink to the left to add a certain amount of tap water and anhydrous calcium chloride, the right to add a certain amount of tap water and sodium fluoride, can configure about $500 \mathrm{mg} / \mathrm{L}$ of $\mathrm{F}$ and $\mathrm{Ca} 2+$. To add a moderate amount of quartz sand in the fluidized bed reactor to speed up the seed calcium fluoride youdao crystallization nucleation.

Electricity open the vacuum pump, so that the left and the right of the sink of the simulated wastewater flow under the action of a vacuum pump to the fluidized bed reactor, after being reaction stability, every once in a while from the fluidized bed reactor by beaker removed after a certain amount of reaction solution.

The reaction solution with the needle out after the $5 \mathrm{ml}$ to $100 \mathrm{ml}$ volumetric flask and configured with his pipetting gun $1 \mathrm{~mol} / \mathrm{L}$ - KNO3 take its $10 \mathrm{ml}$ moved to contain $5 \mathrm{ml} 100 \mathrm{ml}$ volumetric flask of wastewater containing fluoride, and $100 \mathrm{ml}$ volumetric flask with deionized water titration. Finally using ion selective electrode method [17] determination of fluorine ion concentration in wastewater treatment, analysis of experimental results.

Construct simple fluidized crystallization device as shown in figure 1 . 


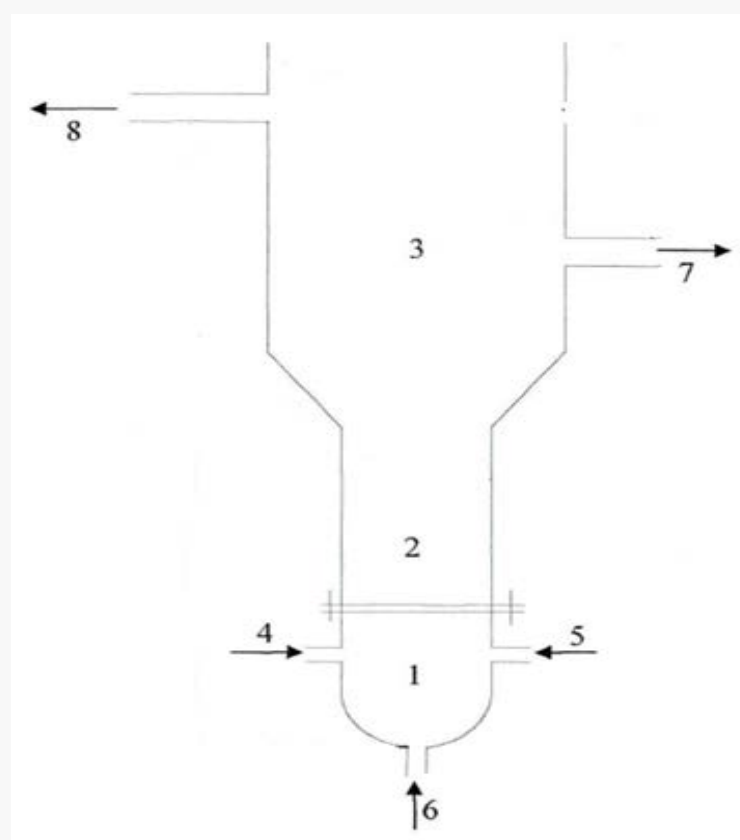

1.Potion mixed zone 2. The wastewater fluidized crystallization reaction zone

3.Clear zone4. Liquid calcium import

5. Wastewater inlet 6. Reflux inlet

7. Return outlet 8. Supernatant fluid outlet

Fig1. The simple structure diagram of Fluidized bed

\section{The results and analysis}

To add 20 g respectively in the fluidized bed reactor size medium and large granular quartz sand, and control of F - and Ca2 + concentration of $500 \mathrm{mg} / \mathrm{L}$. For fluidized bed operation for a period of time after reaching stable, every $30 \mathrm{~min}$, the outlet part of the reaction solution. Control the left and right sides in the sink $\mathrm{F}$ - and $\mathrm{Ca} 2$ + concentration is constant, for different seed size of fluoride in the experiment. Different seed size on the effects of the fluoride in the experimental results are shown in figure 2.

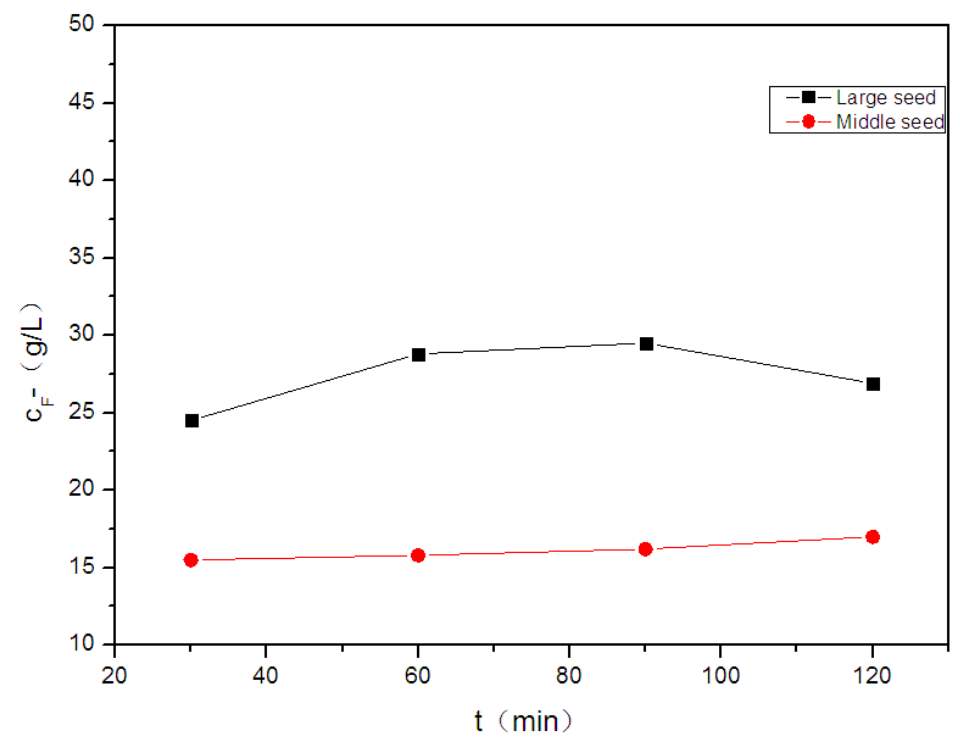

Fig2.Effect of different crystal seed size on effluent concentration of fluoride 
Can be seen from the figure $220 \mathrm{~g}$ of granular quartz sand particle size medium for $20 \mathrm{~g}$ granular quartz sand particle size is larger, the former fluoride in effect is more apparent, treated fluorine ion concentration is generally less than $20 \mathrm{mg} / \mathrm{L}, 30,60,90,90$ min corresponding $C(\mathrm{~F}-)$ were 15.5, 15.8, 16.2, $17 \mathrm{mg} / \mathrm{L}, 20 \mathrm{~g}$ granular quartz sand particle size is larger, however, can only be fluorine ion concentration drops to about $30 \mathrm{mg} / \mathrm{L}$, the main reason is that in the process of growth of calcium fluoride, aggregation and precipitation, while increasing the seed size but did not completely eliminate the precipitation process of some tiny particles, so there is no effective reduce water fluoride ion concentration. We can see from the graph (figure 1) $20 \mathrm{~g}$ size medium granular quartz sand and $20 \mathrm{~g}$ size large granular quartz sand water fluoride ion concentration have some ups and downs, the main reason is due to the actual process of reaction, the effect of vacuum pump to make the two sides of the calcium fluoride wastewater and liquid inlet flow and water levels fall in solution by water pressure has also dropped, to some extent affected the F - and the combination of $\mathrm{Ca} 2+$, in turn, affect the water fluoride ion concentration, it has to do with the results obtained from the central south university ride man li paper roughly the same [18], but the overall water fluoride ion concentration are under control in $20 \mathrm{mg} / \mathrm{L}$. The experimental results show that selecting the appropriate particle size granular quartz sand can effectively control the water fluoride ion concentration, to achieve the desired effect.

The calcium ion concentration of $500 \mathrm{mg} / \mathrm{L}$ unchanged, by controlling the F/Ca were $0.6,0.8$, explore in fluidized bed device under different F/Ca influence on water fluoride ion concentration, time and relationship between water fluoride ion concentration is shown in figure 3.

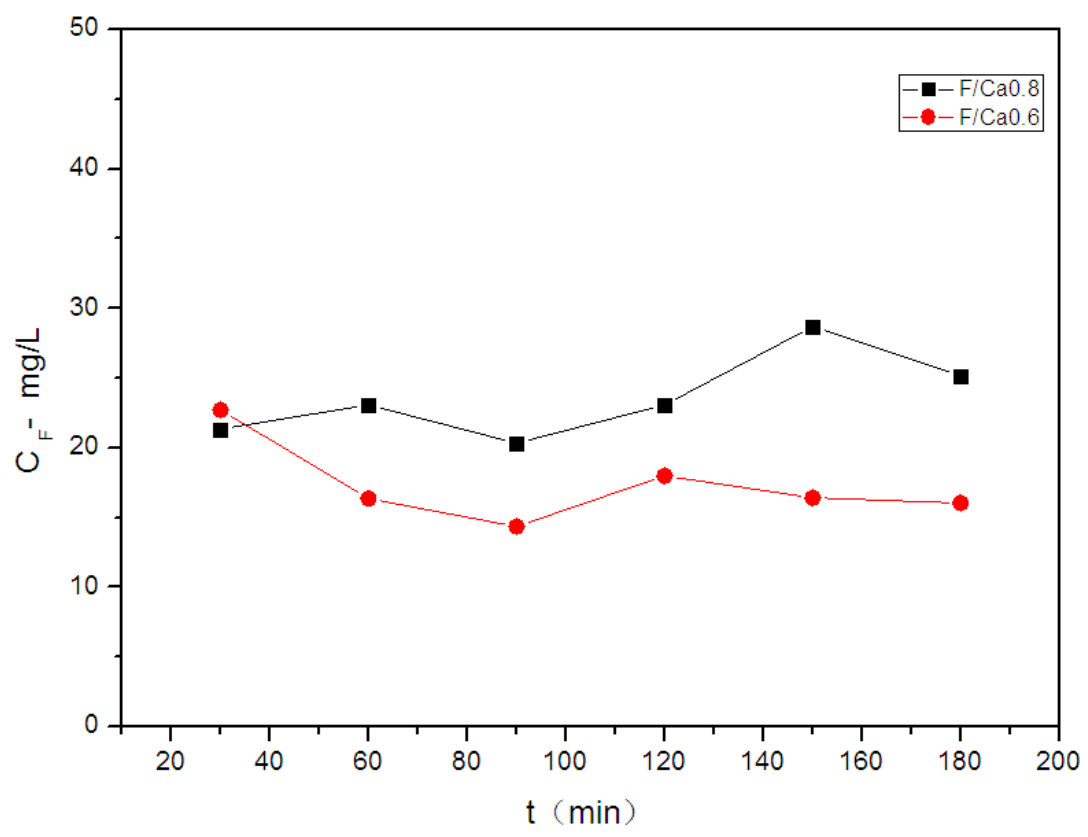

Fig3.Effect of different F/Ca on effluent concentration of fluoride

The experimental results show that, no matter how much F/Ca for outlet fluorine ion concentration remained within 10 to $30 \mathrm{mg} / \mathrm{L}$, the concentration fluctuations generally in about 20 $\mathrm{mg} / \mathrm{L}$, shows that reasonable control $\mathrm{F} / \mathrm{Ca}$ can effectively reduce the water fluorine ion concentration. When $\mathrm{F} / \mathrm{Ca}=0.6$, the water fluoride ion concentration significantly lower $\mathrm{F} / \mathrm{Ca}=0.8$, the main reason is that the bigger the calcium ion concentration, the easier fluorine ion and calcium ion in the solution, solution of $\mathrm{F}-+\mathrm{Ca} 2+\rightleftharpoons \mathrm{CaF} 2$ easily occurs. Removing fluorine ion in the fluidized bed reactor, the better, after a period of time after reaction effluent fluoride ion 
concentration can achieve stable effect. But in actual process, need according to the fluoride ion concentration in the solution to determine the optimal F/Ca.

\section{Conclusion}

(1) fluidized crystallization reactor applied to $500 \mathrm{mg} / \mathrm{L}$ high fluoride wastewater treatment has the feasibility, the operation of the fluidized bed after a period of time after water effect is stable, the calcium fluoride uniform particle size, good for recycling.

(2) to achieve the depth of the high fluoride wastewater removal need comprehensive factors, only a comprehensive factors can determine the effect of fluoride.

(3) the seed size and quality of fluoride in effect is not too big effect, but by changing the size and quality of the seed can control the water fluoride ion concentration is about $15 \mathrm{mg} / \mathrm{L}$, has the good effect of fluoride.

(4) when the F/Ca is 0.6 the Ca2 + concentration of $500 \mathrm{mg} / \mathrm{L}$, the $\mathrm{F}$ - concentration of $300 \mathrm{mg} / \mathrm{L}$ can make $\mathrm{C}(\mathrm{F}-)$ is reduced to about $10 \mathrm{mg} / \mathrm{L}$.

\section{References}

[1] jun-sheng feng, rare earth smelting acidic waste water fluoride in experimental study [D], xi 'an: xi 'an university of science and technology building, 2005.

[2]Aldaco R, Garea A, Irabien A. Calcium fluoride recovery from fluoride wastewater in a fluidized bed reactor. Water Research, 2007, 41(4): 810-818.

[6] Yusuke T, Atsushi L, Junichiro A, et al. Preparation of sorbents containing ettringite phase from concrete sludge and their performance in removing borate and fluoride ions from waste water. Chemical Engineering Journal 2012, 200-202: 338-343.

[7] Vahid K, Ali T, Fatemeh J, et al. Fluoride removal from industrial wastewater using electrocoagulation and its adsorption kinetics. Journal of Hazardous Materials, 2010, 179(1-3): 276-280.

[5] Miguel A, Rosalba F, José L, Israel R. Fluoride removal from drinking water by electrocoagulation in a continuous filter press reactor coupled to a flocculator and clarifier. Separation and Purification Technology, 2014, 134(25): 163-170.

[6] Rahul T, Bal K, Studies on factors affecting fluoride removal from water using passive system. Journal of Environmental Chemical Engineering, 2014, 2(1): 172-176.

[7] Mohapatra M, Anand S, Mishra B, et al. Review of fluoride removal from drinking water. Journal of Environmental Management, 2009, 91(1): 67-77.

[8] Zhou Wuchao FuQuan front, Zhang Yunwu, MaBaoJuan. Fluoride wastewater treatment technology. The research progress of chemical propellant with high polymer material [J]. 2013, 11 (01). 45 to 50

[9]Aldaco R, Garea A, Irabien A. Particle growth kinetics of calcium fluoride in a fluidized bed reactor. Chemical Engineering Science, 2007, 62(11): 2958-2966.

[10] Clifford Y, Taia P, Chen B, et al. Growth Kinetics of CaF2 in a pH -stat Fluidized -bed crystallizer. Journal of Crystal Growth, 2006, 290: 576 -584.

[11] Su C, Abarca R., Luna M, et al. Phosphate recovery from fluidized-bed wastewater by struvite crystallization technology. Journal of the Taiwan Institute of Chemical Engineers, 2014, 45(5): 2395-2402. 
[12] Lee C, Yang W, Hsieh C. Removal of Cu(II) from aqueous solution in a fluidized-bed reactor. Chemosphere, 2004, 57(9): 1173-1180.

[13] Aldaco R, Garea A, Irabien A. Particle growth kinetics of calcium fluoride in a fluidized bed reactor. Chemical Engineering Science, 2007, 62(11): 2958-2966.

[14]Aldaco R, Garea A, Irabien A. Modeling of particle growth: application to water treatment in a fluidized bed reactor. Chemical Engineering Journal, 2007, 134: 66 -71.

[15] Aldaco R, Garea A, Fernndez I, et al. Resources reduction in the fluorine industry: fluoride removal and recovery in a fluidized bed crystallizer. Clean Techn Environ Policy, 2008, 10: 203 -210 .

[16] Battistoni P, Pavan P, Cecchi F, et al. Phosphate removal in real anaerobic supernatants: modeling and performance of a fluidized bed reactor. Water Science and Technology, 1998, 38(1): 275-283.

[17] GB7484-87. The ion selective electrode method [S]. Beijing: the ministry of the People's Republic of China, 1987:1-5.

[18] ride man lee, fluoride wastewater fluidized crystallization processing [D], changsha: central south university, 2011. 